\title{
Corrosion protection of AM60B magnesium alloy by application of electroless nickel coating via a new chrome-free pretreatment
}

\author{
DAVOD SEIFZADEH* and HAMID KAZEMI MOHSENABADI \\ Applied Chemistry Department, University of Mohaghegh Ardabili, Ardabil 5619911367, Iran
}

MS received 21 November 2015; accepted 27 June 2016

\begin{abstract}
Cerium-vanadium (Ce-V) conversion coating was proposed as a new pretreatment for application of electroless Ni-P coating on AM60B magnesium alloy to replace the traditional chromium oxide pretreatment. Morphology and chemical composition of the conversion coating were investigated. The subsequent Ni-P coating deposited on the conversion coating was also characterized by morphology, chemical composition, microstructure, corrosion protection performance and micro-hardness. A uniform, compact and pore-free electroless coating with a moderate concentration of phosphorus $(7.78 \mathrm{wt} \%$ ) was obtained. The electroless coating showed a nobler opencircuit potential than that of the bare alloy during the first $13 \mathrm{~h}$ of immersion in $3.5 \mathrm{wt} \% \mathrm{NaCl}$ solution. Also, the sample plated with the Ce-V conversion coating showed lower corrosion current density than the sample plated with traditional chromium oxide pretreatment. The micro-hardness of the bare alloy was significantly increased after electroless coating. The electroless coating is pore-free and there is suitable adhesion between the coating and alloy substrate.
\end{abstract}

Keywords. Corrosion; protection; AM60B alloy; electroless; conversion coating.

\section{Introduction}

Magnesium is known to be the lightest constructional metal currently available in the world. Recently, magnesium alloys have gained considerable attention for application in aerospace and automobile fields due to high strength-to-weight ratio $[1,2]$. Other outstanding properties of the magnesium alloys include good thermal conductivity, electromagnetic shielding properties and environmental compatibility, which make them as promising materials for application in electrical products [3]. However, the wider applications of the magnesium alloys have been restricted due to some undesirable properties such as poor corrosion, low wear and creep resistance and also low soldering ability. The poor corrosion resistance of the magnesium alloys is the main reason that hinders their usage especially in outdoor applications. Unfortunately, magnesium alloys are extremely susceptible to the galvanic corrosion as a dangerous form of corrosion, which causes severe pitting and unattractive appearance [4].

Corrosion resistance of the magnesium alloys can be increased by suitable surface coating. Among all the protective coatings, electroless $\mathrm{Ni}-\mathrm{P}$ coatings have shown high performance in some industrial applications mostly due to their excellent corrosion and wear resistance. There are a number of challenges that must be faced in order to apply $\mathrm{Ni}-\mathrm{P}$ electroless coating on the magnesium alloys, including high chemical activity, rapid formation of a loose oxide layer (with low electrical conductivity) and electrochemical

*Author for correspondence (seifzadeh@uma.ac.ir) heterogeneity of the alloy surface $[1,4,5]$. Therefore, a special pretreatment is required before application of the electroless coating on the magnesium alloys. One traditional pretreatment method for the electroless plating of the magnesium alloys consists of the Dow process, which can be described by the following steps [6]:

mechanical polishing $\rightarrow$ degreasing in an alkaline solution $\rightarrow$ pickling in chromic acid and nitric acid solutions $\rightarrow$ zinc immersion $\rightarrow$ cyanide copper plating $\rightarrow$ electroless plating.

Cyanide copper plating in the Dow process is harmful to health. Also, the replaced zinc layer shows low adherent strength, especially in the case of the alloys with high aluminium content.

An alternative and more recent approach is the direct electroless process, which can be described as follows [6,7]: mechanical polishing $\rightarrow$ degreasing in an alkaline solution $\rightarrow$ pickling in $\mathrm{CrO}_{3}+\mathrm{HNO}_{3}$ solution $\rightarrow$ activation in $\mathrm{HF}$ solution $\rightarrow$ electroless plating in fluoride-containing bath.

The purposeof the $\mathrm{CrO}_{3}+\mathrm{HNO}_{3}$ pickling process is to remove superficial oxides from the alloy surface and appropriately coarsening the surface to increase the degree of mechanical interlocking between the electroless coating and the magnesium substrate. The traditional chromate pickling solution can form a kind of conversion coating on the surface and therefore, it protects the magnesium alloy from severe corrosion attack [8]. However, the use of the chromium oxide increases the danger in the direct electroless 
plating and therefore many researches have focused on the environment- and health-friendly alternative materials. Elsentriecyz and Azumi [9] used a special pretreatment for direct electroless nickel plating on AZ91D magnesium alloy consisting of the pickling in $\mathrm{HF}$ and $\mathrm{HCl}$ solutions, conversion coating in molybdate bath and then activation in $\mathrm{HF}$ solution. They obtained interesting results but it appears that the anticorrosive resistance of the applied coating is not sufficient. This is because the corrosion potential of the coated sample after about $30 \mathrm{~min}$ immersion in $3.5 \mathrm{wt} \% \mathrm{NaCl}$ solution is more negative than $-0.5 \mathrm{~V}$ with respect to $\mathrm{Ag}-\mathrm{AgCl}$ reference electrode, probably due to penetration of the corrosive solution and formation of galvanic effect between the magnesium substrate and the electroless coating. Moreover, a rough electroless layer with a convex-concave structure was obtained due to the coarse surface of the molybdate conversion coating. Zhang et al [10] investigated the electroless plating of the $\mathrm{Mg}-10 \mathrm{Li}-1 \mathrm{Zn}$ alloy using another chrome-free pretreatment. First, the alloy samples were etched in a $\mathrm{H}_{3} \mathrm{PO}_{4}+\mathrm{HNO}_{3}$ solution (instead of the traditional $\mathrm{CrO}_{3}+\mathrm{HNO}_{3}$ solution). Afterwards, the samples were activated in HF solution before final electroless Ni-P plating in a fluoride-containing bath. The obtained Ni-P coating was amorphous and obviously improved the corrosion resistance of the $\mathrm{Mg}-10 \mathrm{Li}-1 \mathrm{Zn}$ alloy. Zhang et al [11] and Lian et al [12] introduced two chrome-free pretreatments based on a phosphate-manganese and phosphate-molybdate conversion coating, respectively, as pretreatment for electroless $\mathrm{Ni}-\mathrm{P}$ plating on the AZ91D magnesium alloy. Also, Huo et al [13] introduced another chrome-free pretreatment based on the stannate conversion coating and subsequent sensitization and activation in acidic $\mathrm{SnCl}_{2}$ and ethanolic $\mathrm{PdCl}_{2}$ solutions, respectively. Moreover, other researchers have investigated some different chrome-free pretreatments for electroless $\mathrm{Ni}-\mathrm{P}$ plating on the magnesium alloys $[5,8,14-17]$. However, it appears that more investigation is needed to develop safe and effective routes for electroless Ni-P plating on the magnesium alloys. Moreover, in most of the published works, only short-term corrosion tests were performed; hence their results cannot be used for evaluating the real corrosion protection performance of the applied coatings. As mentioned elsewhere [1], existence of small pores or defects in the electroless Ni-P coatings on the magnesium substrates is one of the most important factors that lowers its corrosion protection performance. It has been known that the $\mathrm{Ni}-\mathrm{Mg}$ system is a typical example of the cathodic coating on the anodic substrate. Therefore, any electrolytic contact between the nickel coating and the magnesium substrate through the pores, defects or grain boundaries will cause significant shift in the corrosion potential towards the more negative direction due to the formation of a strong galvanic effect. The amount of the diffused corrosive solution generally increases with immersion time; therefore, the galvanic effect is not strong at the initial immersion times. Thus, it appears that the real protection performance of the applied coatings must be evaluated by performing long-term immersion tests in corrosive solutions.
The corrosion protection of the magnesium alloys by cerium [18-24] and vanadium [25-28] conversion coatings has been relatively widely studied. Recently, Jiang et al [29] introduced a new bath containing both sodium metavanadate $\left(\mathrm{NaVO}_{3}\right)$ and cerium nitrate hexahydrate $\left(\mathrm{Ce}\left(\mathrm{NO}_{3}\right)_{3} \cdot 6 \mathrm{H}_{2} \mathrm{O}\right)$ to develop a corrosion-protective cerium-vanadium $(\mathrm{Ce}-\mathrm{V})$ conversion film on the magnesium alloy as an environmentfriendly alternative for the traditional chromate conversion coating. The obtained results are interesting since the corrosion resistance of the magnesium alloys was significantly increased after treatment in $\mathrm{Ce}-\mathrm{V}$ bath. In addition, it was found that the applied conversion coating has better protection performance than the chromate conversion coating. Therefore, it may be used as an environment-friendly alternative to the chromate conversion coating in the pretreatment route for direct electroless plating on the magnesium alloys.

In this work, $\mathrm{Ce}-\mathrm{V}$ conversion coating plus HF activation pretreatment has been proposed to replace the traditional chromium oxide plus HF pretreatment for application of the electroless nickel layer on the AM60B magnesium alloy. Morphology, microstructure and chemical composition of the applied coating were analysed by scanning electron microscopy (SEM), X-ray diffraction (XRD) and energydispersive X-ray spectroscopy (EDS) methods. Also, the anticorrosion performance of the coatings was evaluated by performing potentiodynamic polarization and long-term open-circuit potential (OCP) measurements in $3.5 \mathrm{wt} \% \mathrm{NaCl}$ solution.

\section{Experimental}

\subsection{Plating}

The samples used in this work were prepared from an AM60B magnesium alloy bar with dimensions of $30 \mathrm{~mm} \times$ $15 \mathrm{~mm} \times 15 \mathrm{~mm}$. The chemical composition of the alloy samples was determined by the EDS method; it contained $6.33 \% \mathrm{Al}, 0.68 \% \mathrm{Zn}, 0.24 \% \mathrm{Mn}$ and the balance of $\mathrm{Mg}$ mainly (wt\%). The samples were polished with emery papers (no. 100-1000) and then rinsed with distilled water before being taken into the pretreatment and electroless processes. Afterwards, the alloy samples were ultrasonically cleaned in pure acetone for $15 \mathrm{~min}$ at $40^{\circ} \mathrm{C}$. The samples were degreased in $45 \mathrm{~g} \mathrm{l}^{-1} \mathrm{NaOH}+10 \mathrm{~g} \mathrm{l}^{-1} \mathrm{Na}_{3} \mathrm{PO}_{4}$ solution for $15 \mathrm{~min}$ at $60^{\circ} \mathrm{C}$. The samples were subsequently etched in $0.8 \%(\mathrm{~V} / \mathrm{V})$ $\mathrm{HNO}_{3}(63 \mathrm{wt} \%)$ solution to remove any oxide layer. Also the acidic etching makes the alloy surface coarse, which increases the mechanical interlocking between the final coating and the substrate. Then, the $\mathrm{Ce}-\mathrm{V}$ conversion coating was applied for $20 \mathrm{~min}$ at $50^{\circ} \mathrm{C}$ using a solution containing $2.4 \mathrm{gl}^{-1} \mathrm{NaVO}_{3}$ and $4 \mathrm{~g} \mathrm{l}^{-1} \mathrm{Ce}\left(\mathrm{NO}_{3}\right)_{3} \cdot 6 \mathrm{H}_{2} \mathrm{O}$ with a $\mathrm{pH}$ value of 2.5 (adjusted by $\mathrm{HNO}_{3}$ ). Next, the samples were activated in $350 \mathrm{ml}^{-1} \mathrm{HF}(40 \% \mathrm{~V} / \mathrm{V})$ for $20 \mathrm{~min}$ at room temperature. Finally, the electroless coating was applied from a bath containing $15 \mathrm{~g} \mathrm{l}^{-1} \mathrm{NiSO}_{4} \cdot 6 \mathrm{H}_{2} \mathrm{O}, 14 \mathrm{gl}^{-1} \mathrm{Na}_{2} \mathrm{H}_{2} \mathrm{PO}_{2} \cdot \mathrm{H}_{2} \mathrm{O}$, $13 \mathrm{gl}^{-1} \mathrm{NaC}_{2} \mathrm{H}_{3} \mathrm{O}_{2}, 8 \mathrm{gl}^{-1} \mathrm{NH}_{4} \mathrm{HF}_{2}, 12 \mathrm{ml}^{-1} \mathrm{HF}(40 \%$ $\mathrm{V} / \mathrm{V}$ ) and $\mathrm{NH}_{3}$ (for adjusting $\mathrm{pH}$ value on 6.4). A small amount of $\mathrm{CuSO}_{4} \cdot 5 \mathrm{H}_{2} \mathrm{O}\left(0.2 \mathrm{~g} \mathrm{l}^{-1}\right)$ was also added to the 
electroless plating bath to achieve high plating rate and therefore more protective electroless layer [30]. The electroless plating was carried out at $65^{\circ} \mathrm{C}$ for $3 \mathrm{~h}$ in $250 \mathrm{ml}$ plating bath.

\subsection{Surface characterization}

A SEM instrument (LEO, VP 1430) at high vacuum and $15 \mathrm{kV}$ EHT was used to examine the surface and crosssectional morphologies of the applied coating. Also, the morphology of the alloy sample after $\mathrm{Ce}-\mathrm{V}$ conversion coating treatment was studied. The chemical composition of the conversion and final electroless coatings was determined by the EDS (RÖNTEC GmbH, Germany) method. An XRD analyzer (Philips Xpert) with $\mathrm{Cu} K \alpha$ radiation $(\lambda=$ $0.154178 \mathrm{~nm}$ ) was also used to study the microstructure of the electroless coating.

\subsection{Corrosion tests}

Electrochemical corrosion tests were carried out in $3.5 \mathrm{wt} \%$ $\mathrm{NaCl}$ solution using a $\mu$ autolab3 Potentiostat-Galvanostat, which was supported by Nova 1.6 software. A classical threeelectrode electrochemical cell with an alloy sample as working electrode, platinum sheet $\left(1 \mathrm{~cm}^{2}\right)$ as counter-electrode and a saturated $\mathrm{Ag}-\mathrm{AgCl}$ electrode as reference was used. Prior to the electrochemical measurements, working electrodes were mounted with a thick epoxy coating, leaving an exposed area of $1 \mathrm{~cm}^{2}$.

The OCP values of the bare and coated alloy samples were measured over immersion time in the corrosive solution.

Before the potentiodynamic polarization tests, the working electrodes were immersed in the corrosive solution for about $60 \mathrm{~min}$ to reach the steady-state potential. Then, the potential of the working electrode was scanned from the cathodic to anodic direction at a scan rate of $1 \mathrm{mV} \mathrm{s}^{-1}$. The obtained polarization curves were transformed to Tafel format and the corrosion current densities $\left(j_{\text {corr }}\right)$ were calculated by Tafel extrapolation of the cathodic branch [31]. The polarization measurements were repeated three times and the results were averaged.

The results of the corrosion tests were compared with those obtained for the electroless coating applied on AM60B magnesium alloy in the same manner as described in Section 2.1 but using the traditional $\mathrm{CrO}_{3}$ pretreatment (immersion in $60 \mathrm{gl}^{-1} \mathrm{CrO}_{3}$ and $50 \mathrm{mll}^{-1} \mathrm{HNO}_{3} 63 \mathrm{wt} \%$ solution for $30 \mathrm{~s}$ at room temperature) instead of the $\mathrm{Ce}-\mathrm{V}$ pretreatment.

All the electrochemical tests were performed at room temperature $\left(\approx 22^{\circ} \mathrm{C}\right)$ under ambient pressure without any agitation of the corrosive solution. The volume of the corrosive solution for each test was about $200 \mathrm{ml}$.

\subsection{Micro-hardness}

The micro-hardness of the bare and the coated alloy substrates was measured using a micro-hardness tester with
Vickers indenter (WOLPERT) at a load of $100 \mathrm{~g}$ for a duration of $10 \mathrm{~s}$. The average micro-hardness values were taken from at least 3 tests for each sample.

\subsection{Porosity test}

As mentioned above, there is a big potential difference between the nickel and magnesium; therefore, electroless nickel coating on the magnesium alloy substrate must be pore-free to avoid the galvanic corrosion risk. Thus a porosity test was carried out to examine the porousness of the applied $\mathrm{Ni}-\mathrm{P}$ coating as described elsewhere [12]. First, a filter paper with a size of $1 \mathrm{~cm}^{2}$ was soaked in an aqueous solution containing $10 \mathrm{~g}^{-1} \mathrm{NaCl}, 106 \mathrm{~g} \mathrm{l}^{-1}$ ethyl alcohol and $0.1 \mathrm{~g} \mathrm{l}^{-1}$ phenolphthalein and then pasted on the plated sample for $10 \mathrm{~min}$. Afterwards, the filter paper was removed from the surface and the possible red spots were noted on the surface of the coating. The porosity of the coating can be reported by the ratio of the red spots to the area previously pasted by the filter paper. This method is based on a simple principle. If there are any pores in the coating, the corrosive electrolyte will penetrate towards the alloy substrate and the magnesium corrosion starts immediately. As the main cathodic reaction, reduction of water starts simultaneously, which causes accumulation of hydroxyl ions and they are responsible for red spots.

\subsection{Adhesion test}

Thermal shock method was used to evaluate the adhesion of the applied coating according to ASTM B 733-04 [32]. The plated alloy sample was heated to $200^{\circ} \mathrm{C}$ in a digital furnace and then immediately quenched in room temperature water. The process was repeated 30 times and then the sample was examined for blister or crack formation on the surface.

\section{Results and discussion}

\subsection{Ce-V conversion coating}

SEM morphological image of the alloy surface after $\mathrm{Ce}-\mathrm{V}$ conversion coating pretreatment is shown in figure 1 . It is obvious that the $\mathrm{Ce}-\mathrm{V}$ pretreatment proceeds through the formation of a cracked conversion coating with nodular structure. Chemical composition of the conversion film was analysed by the EDS method. The results showed that the conversion film was mainly composed of the alloying atoms, including $\mathrm{Mg}$ (9.53 wt\%), Al (2.52 wt\%), $\mathrm{Zn}(0.99 \mathrm{wt} \%)$ and $\mathrm{Mn}(0.4 \mathrm{wt} \%)$ together with the $\mathrm{V}(22.33 \mathrm{wt} \%)$ and $\mathrm{Ce}$ (43.06 wt $)$ atoms. Also, a considerable amount of the $\mathrm{O}$ atoms $(21.16 \mathrm{wt} \%)$ was observed in the conversion coating. A possible mechanism for the formation and growth of the $\mathrm{Ce}-\mathrm{V}$ conversion film on a magnesium alloy has been discussed in sufficient detail by Jiang et al [29], which will be briefly explained as follows. 


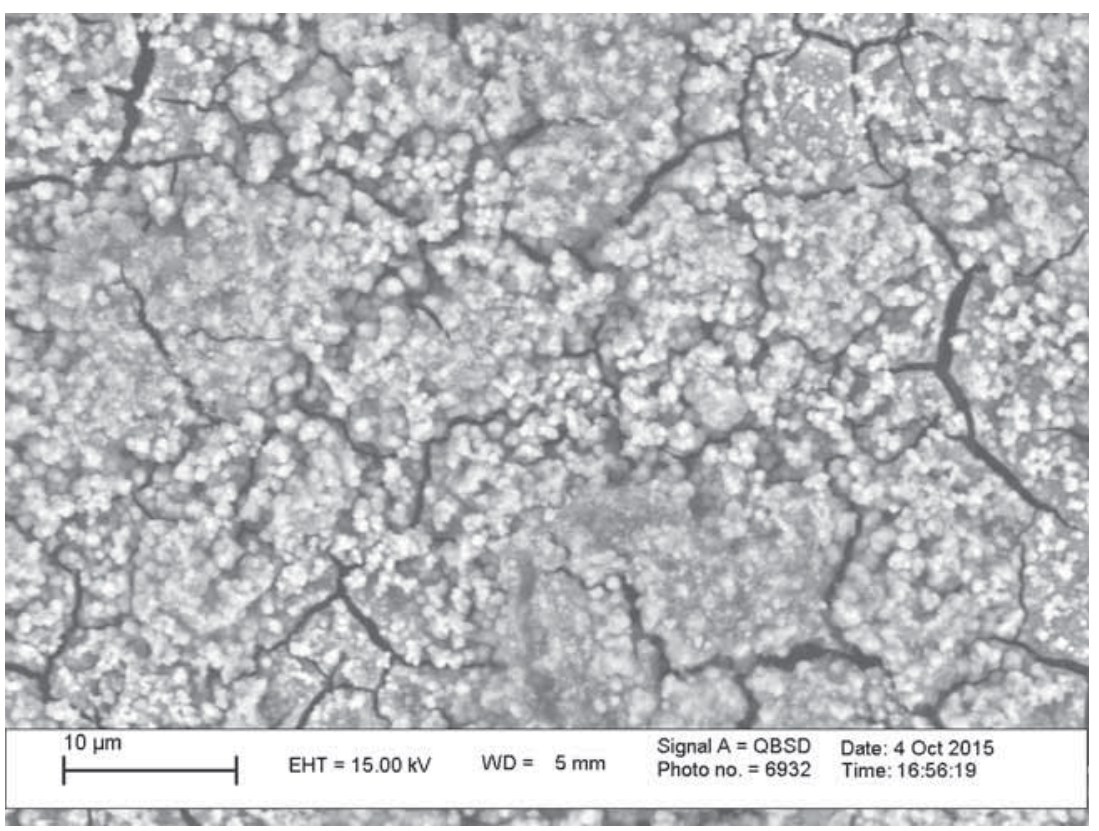

Figure 1. Surface morphology of the alloy sample after conversion coating treatment obtained by the SEM method.

The first process that immediately takes place after immersion in the conversion coating bath is corrosion of the alloy substrate:

$$
\begin{aligned}
& \mathrm{Mg} \rightarrow \mathrm{Mg}^{2+}+2 \mathrm{e}^{-} \\
& 2 \mathrm{H}_{2} \mathrm{O}+2 \mathrm{e}^{-} \rightarrow \mathrm{H}_{2}+2 \mathrm{OH}^{-}
\end{aligned}
$$

The anodic dissolution of only magnesium as the main metallic alloying element is given. However, it should be noted that the oxidation of other alloying elements $(\mathrm{Al}, \mathrm{Zn}$ and $\mathrm{Mn}$ ) is also possible. Magnesium is a very active metal; therefore, the corrosion process is fast enough to take the $\mathrm{pH}$ at the substrate/electrolyte interface to a high level even after a shortterm immersion. Under the highly alkaline condition at the interface, the hydroxides of the alloying elements are precipitated. Also, $\mathrm{Ce}^{3+}$ ions react with the hydroxyl ions to create crystal nucleus of the cerium hydroxide on the alloy surface and then the nucleation centres grow to cover the alloy surface. Simultaneously, $\mathrm{VO}_{2}^{+}$cations (the predominant form of the vanadium in a sodium metavanadate solution when the concentration is $2.4 \mathrm{~g} \mathrm{l}^{-1}$ and the $\mathrm{pH}$ is 2.5 ) react with water to produce vanadium hydroxides on the alloy surface:

$$
\begin{aligned}
& \mathrm{VO}_{2}^{+}+2 \mathrm{H}_{2} \mathrm{O} \rightarrow \mathrm{VO}(\mathrm{OH})_{3}+\mathrm{H}^{+} \\
& \mathrm{VO}(\mathrm{OH})_{3}+2 \mathrm{H}_{2} \mathrm{O} \rightarrow \mathrm{VO}(\mathrm{OH})_{3}\left(\mathrm{OH}_{2}\right)_{2}
\end{aligned}
$$

The vanadium hydroxides are not stable in the conversion bath condition and their spontaneous polymerization takes place to form a stable polymeric structure with $\mathrm{V}(\mathrm{V})-\mathrm{O}-\mathrm{V}$ (V) linkages. It is believed that this polymeric structure is able to adsorb or capture the other hydroxides before they grow up. Therefore, all of the hydroxides simultaneously deposit on the alloy surface to form a conversion film. Then the metallic hydroxides dehydrate to form the corresponding oxides and this process leads to the formation of cracks in the coating.

\subsection{Electroless plating}

Surface morphology of the applied electroless Ni-P coating was observed by SEM at low (figure 2a) and high (figure 2b) magnifications. It is obvious that uniform, compact and porefree electroless coating was obtained. The electroless coating showed a spherical nodular structure with random distribution of the nodule size. The nodules contain numerous smaller sub-nodules and there were no defects at the grain boundaries. It appears that the proposed conversion coating reduces the corrosion rate and potential heterogeneity of the magnesium alloy; thus, an electroless layer with fine and dense structure can be obtained. Also, the cracks on the conversion coating play a major role in the electroless plating. The electrochemical potential of the nickel ions is more positive than that of the alloying elements; therefore, nickel nucleation centres can be formed at the conversion coating pores via replacement reactions where the plating solution is in direct contact with the alloy substrate:

$$
\begin{aligned}
& \mathrm{Mg}+\mathrm{Ni}^{2+} \rightarrow \mathrm{Mg}^{2+}+\mathrm{Ni} \\
& 2 \mathrm{Al}+3 \mathrm{Ni}^{2+} \rightarrow 2 \mathrm{Al}^{3+}+3 \mathrm{Ni} \\
& \mathrm{Zn}+\mathrm{Ni}^{2+} \rightarrow \mathrm{Zn}^{2+}+\mathrm{Ni} \\
& \mathrm{Mn}+\mathrm{Ni}^{2+} \rightarrow \mathrm{Mn}^{2+}+\mathrm{Ni}
\end{aligned}
$$



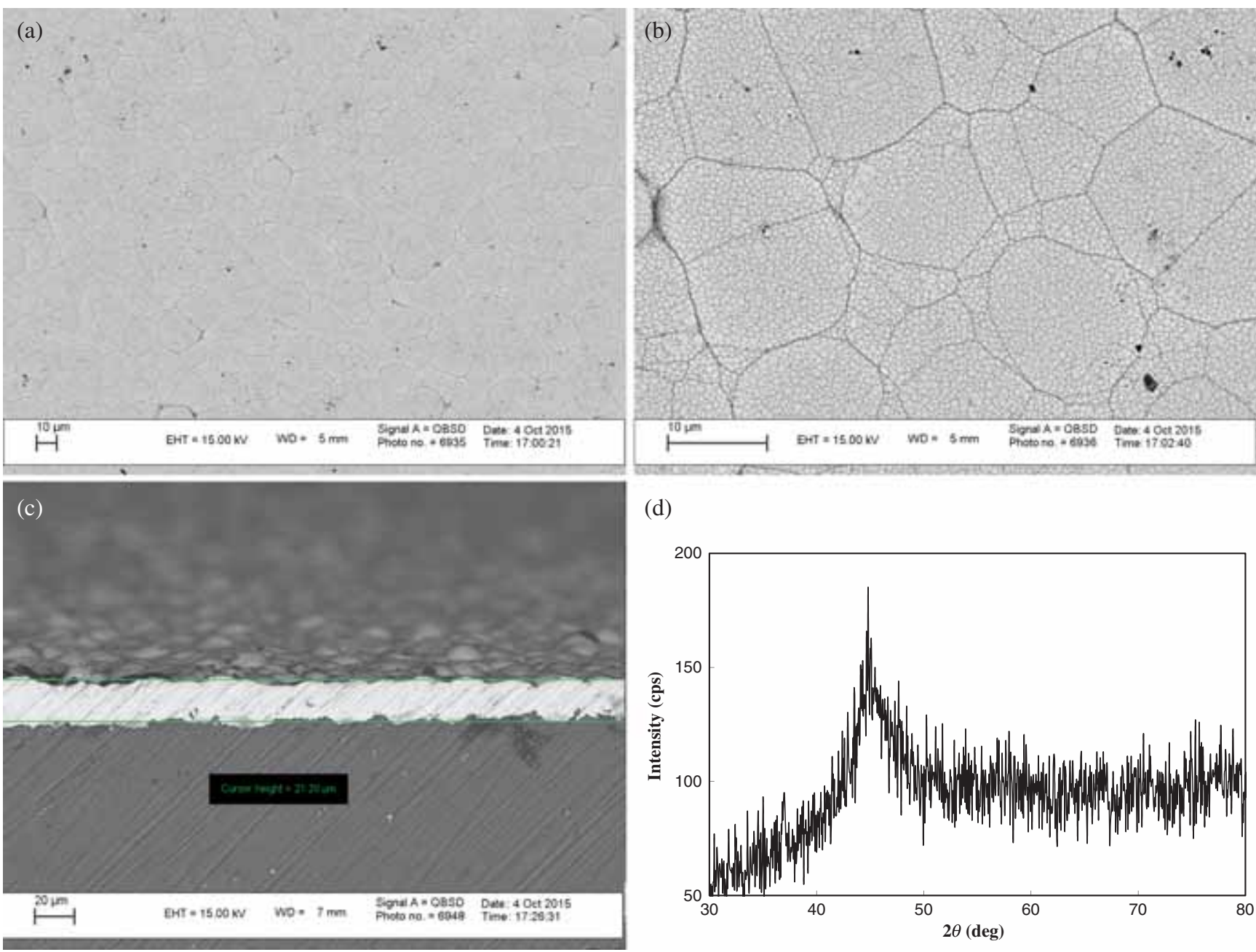

(d)

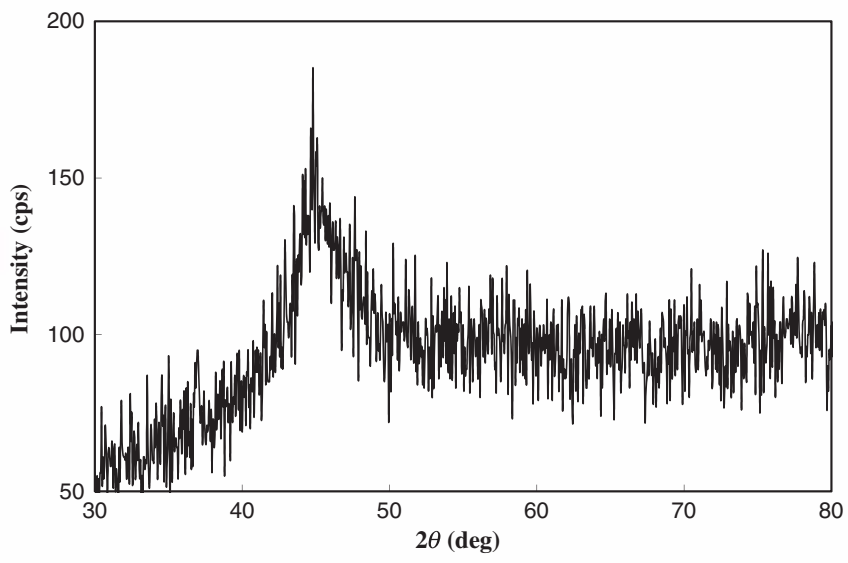

Figure 2. Morphological SEM images at (a) low and (b) high magnification, (c) cross-sectional SEM image and (d) XRD pattern of the electroless coating.

Then the nickel nuclei act as catalytic centres for the main electroless reactions, which can be described by the following mechanism [33]:

$$
\begin{aligned}
& 2 \mathrm{H}_{2} \mathrm{PO}_{2}^{-}+2 \mathrm{H}_{2} \mathrm{O}+\mathrm{Ni}^{2+} \rightarrow \mathrm{Ni}+2 \mathrm{H}_{2} \mathrm{PO}_{3}^{-}+2 \mathrm{H}^{+}+\mathrm{H}_{2} \\
& \mathrm{H}_{2} \mathrm{PO}_{2}^{-}+\mathrm{H}_{2} \mathrm{O} \rightarrow \mathrm{H}_{2} \mathrm{PO}_{3}^{-}+\mathrm{H}_{2} \\
& 4 \mathrm{H}_{2} \mathrm{PO}_{2}^{-}+\mathrm{H}^{+}+\mathrm{H}_{2} \mathrm{O} \rightarrow 3 \mathrm{H}_{2} \mathrm{PO}_{3}^{-}+\mathrm{P}+\frac{5}{2} \mathrm{H}_{2}
\end{aligned}
$$

The cross-sectional morphology of the coating was also observed (figure 2c). It can be seen that the electroless layer was firmly attached to the alloy substrate and there were no cracks or defects in the coating-substrate interface. Also, average thickness of the electroless coating was about $21 \mu \mathrm{m}$.

Chemical composition of the electroless coating was analysed by EDS. The results showed that the electroless coating was mainly composed of nickel $(91.24 \mathrm{wt} \%)$ and phosphorous $(7.78 \mathrm{wt} \%)$. A moderate concentration of the phosphorus was determined by quantitative EDS analysis; therefore, the applied electroless coating tends to be semi-amorphous with a mixed amorphous and crystalline microstructure [2,34]. Also, a small amount of copper $(0.98 \mathrm{wt} \%)$ can be seen in the coating due to the presence of the copper sulphate in the electroless bath. A possible mechanism to explain the codeposition of the copper can be described by the following reaction:

$$
\mathrm{Cu}^{2+}+2 \mathrm{H}_{2} \mathrm{PO}_{2}^{-}+2 \mathrm{H}_{2} \mathrm{O} \rightarrow \mathrm{Cu}+2 \mathrm{H}_{2} \mathrm{PO}_{3}^{-}+2 \mathrm{H}^{+}+\mathrm{H}_{2}
$$

Moreover, some copper atoms may be deposited due to the replacement reaction between the primary deposited $\mathrm{Ni}$ atoms and the copper ions in the plating solution since the reduction potential of copper is more positive than that of nickel:

$$
\mathrm{Ni}+\mathrm{Cu}^{2+} \rightarrow \mathrm{Ni}^{2+}+\mathrm{Cu}
$$

The XRD pattern of the electroless coating on the magnesium alloy was also obtained (figure $2 \mathrm{~d}$ ). The XRD pattern showed a broad peak at around $2 \theta=45^{\circ}$, indicating 
an amorphous structure possibly with small microcrystalline areas [34], and therefore the result was identical to those obtained by the SEM and EDS analyses. Also, the peaks corresponding to metallic copper were not observed more probably due to the low content of copper in the coating.

\subsection{Corrosion tests}

Corrosion protection performance of the applied coatings was examined by two different electrochemical methods in the $3.5 \mathrm{wt} \% \mathrm{NaCl}$ solution.

The OCP measurement is a simple but powerful electrochemical technique for monitoring the corrosion of the metallic coatings on immersion in corrosive solutions. This method is very useful in the case of the cathodic metallic coatings, which are nobler than the substrate. The large electrochemical potential difference between the magnesium alloy and electroless nickel coating predicts strong galvanic effect; therefore gradual diffusion of the corrosive solution through the pores or grain boundaries will cause significant changes in the OCP towards the more negative direction. In fact, the OCP monitoring of the immersion in the corrosive media gives us very useful information on the extent of the pores or defects in the electroless coating. Figure 3 a shows
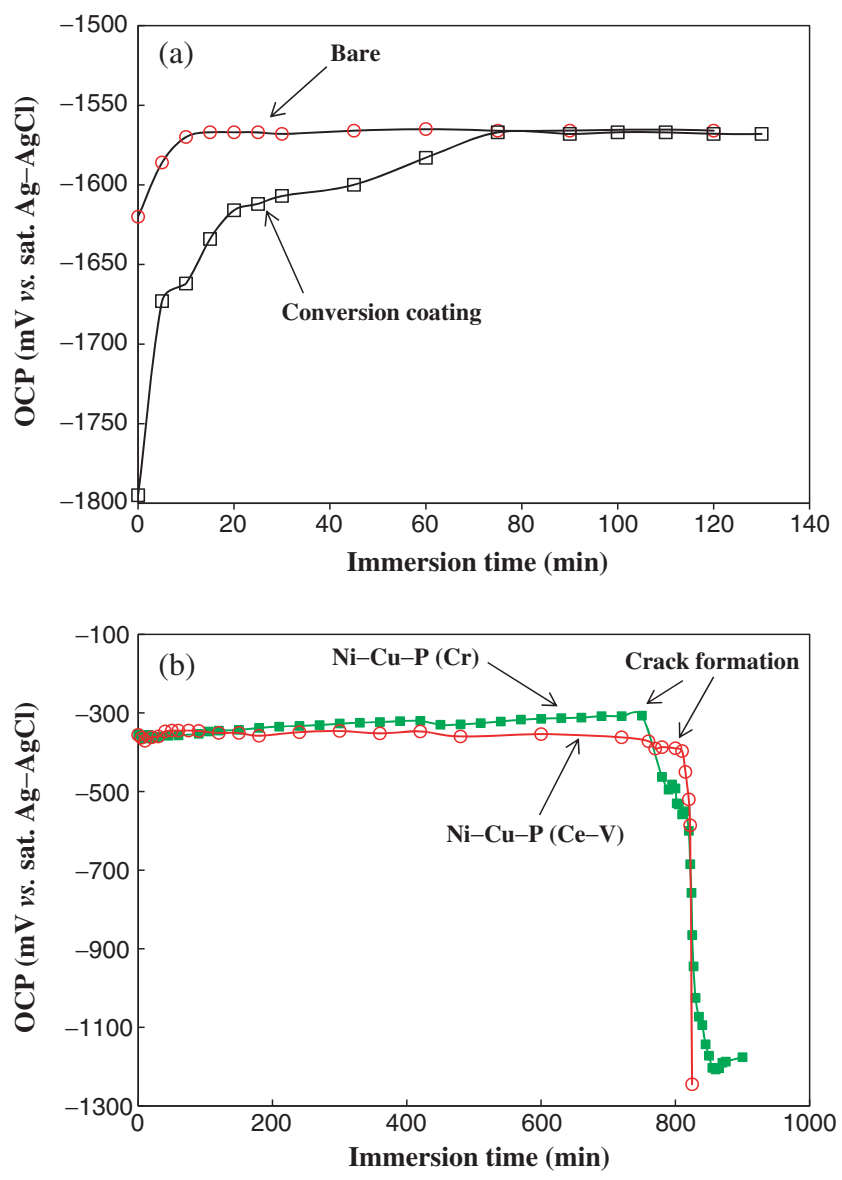

Figure 3. Change of OCP with immersion time in $3.5 \mathrm{wt} \% \mathrm{NaCl}$ solution: (a) bare and conversion coating and (b) electroless coating. the changes of the OCP vs. time after immersion of the bare alloy before and after conversion coating treatment in the $3.5 \mathrm{wt} \% \mathrm{NaCl}$ solution.

As can be seen, the OCP (or corrosion potential) values of the bare alloy were quickly shifted towards the positive direction during the initial $15 \mathrm{~min}$ of the immersion; then they reached a steady-state value (around $-1.560 \mathrm{~V}$ ). Although the initial OCP value for the conversion-coated sample was more negative than that of the bare sample, the same trend and also the same final OCP values can be also seen. The shift of the OCP values towards the more positive direction could be relevant to the formation of the magnesium hydroxide on the alloy surface through the precipitation of magnesium ions, wherein hydroxyl ions are produced due to the reduction of water [35].

In the case of the electroless coating (figure $3 b$ ), a more noble corrosion potential can be observed at least for the first $12 \mathrm{~h}$ of the immersion, indicating significant improvement of the corrosion resistance. When a galvanic corrosion cell is formed, anodic (metal oxidation) and cathodic (reduction of corrosive species) reactions take place simultaneously on the metal surface; therefore, both of them will change the potential to a mixed value called the corrosion potential. The current densities of the anodic and cathodic reactions in the corrosion potential are equal $\left(j_{\mathrm{c}}=j_{\mathrm{a}}=\right.$ corrosion current). As the main kinetic parameter, corrosion current density determines the real corrosion rate of a metal. However, the corrosion potential is a significant thermodynamic parameter, which shows the tendency of a metal to corrosion, so that the metals with more positive (or noble) potential generally have lower corrosion rate. Therefore, the more noble corrosion potential of the $\mathrm{Ni}-\mathrm{P}$ coating with respect to the bare alloy indicates its much lower tendency to corrosion.

However, several steps can be seen in the corrosion potential vs. immersion time plot. The corrosion potential was about $-0.356 \mathrm{~V}$ immediately after immersion of the sample in the corrosive solution but it slowly shifted towards the negative direction during the first $10 \mathrm{~min}$ of the immersion more probably due to the gradual penetration of the corrosive solution through the grain boundaries. However, the level of the penetrated corrosive solution was very low since the corrosion potential was very noble yet. After the initial negative shift, the corrosion potential slowly shifted towards the positive direction until its value reached about $-0.345 \mathrm{~V}$ after $50 \mathrm{~min}$ immersion. The slight ennoblement of the corrosion potential may be related to the filling of diffusion pathways of the corrosive solution with corrosion products. However, the corrosion damage was very low in this step and there was no obvious pore, pit or crack on the coating. Further, the OCP values changed in a slightly periodic or irregular manner around the value of $-0.350 \mathrm{~V}$ probably due to competition between the filling of the electrolyte pathways with corrosion products and creation of new pathways for the corrosive solution. Finally, a single centre for evolution of the hydrogen gas bubble was formed on the coating and the corrosion potential rapidly shifted towards more negative values after about $13 \mathrm{~h}$ and simultaneously, a hardly distinguishable 
macroscopic pore was formed on the coating. Fast evolution of the gas bubbles continued at the pore area, whereas the other areas of the coating were stable without any gas evolution centre or corrosion defects. These results indicated that the diffusion extent of the corrosive solution increased after $13 \mathrm{~h}$ immersion; therefore, the corrosion rate increases at the substrate-coating interface, which causes rapid formation of considerable amount of hydrogen gas bubbles under electroless coating. Rapid formation of gas bubbles increases the internal stress in the coating, which causes sudden formation of the macroscopic crack and therefore, penetration of large amount of the corrosive solution. Diffusion of the large amount of the corrosive solution causes the formation of strong galvanic effect, which increases the corrosion rate of the alloy substrate at the cracked area. However, other places on the coated sample were mainly undamaged even after several hours.

The same behaviour was observed for the sample plated via chromium oxide pretreatment (figure $3 \mathrm{~b}$ ). The sample showed stable OCP values over approximately $12 \mathrm{~h}$. After this immersion time, a single gas bubble and then macroscopic crack formed on the surface.

Potentiodynamic polarization plots were also recorded to obtain the corrosion current density values for the bare and coated samples after $1 \mathrm{~h}$ immersion in the corrosive solutions (figure 4). Similar polarization behaviours were observed before and after conversion coating treatment. But considerably lower currents were recorded for the alloy sample after

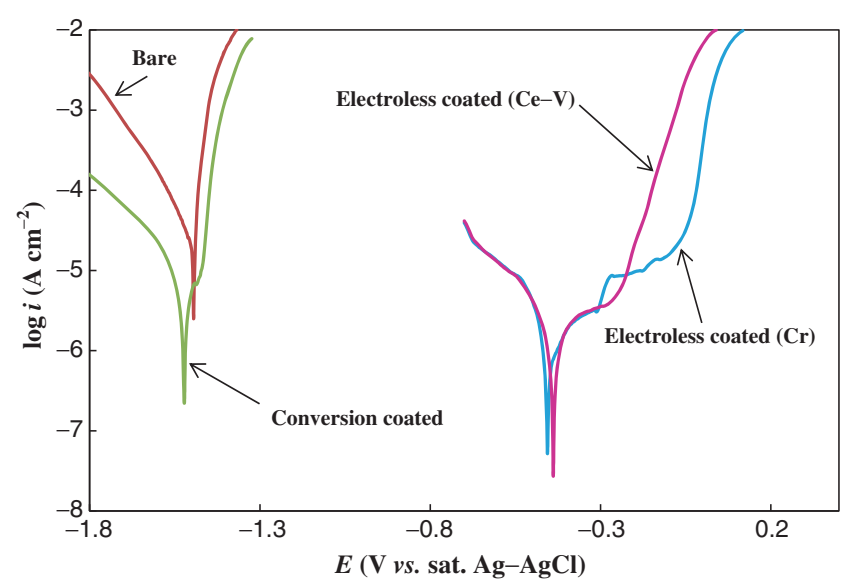

Figure 4. Potentiodynamic polarization curves of the bare, conversion coating and electroless $\mathrm{Ni}-\mathrm{P}$ coatings after $1 \mathrm{~h}$ immersion in $3.5 \mathrm{wt} \% \mathrm{NaCl}$ solution. conversion coating treatment. Corrosion process of the alloy sample either before or after conversion coating treatment can be described as follows [36]:

$$
\begin{aligned}
& 2 \mathrm{Mg} \rightarrow 2 \mathrm{Mg}^{+}+2 \mathrm{e}^{-} \\
& 2 \mathrm{Mg}^{+}+2 \mathrm{H}_{2} \mathrm{O} \rightarrow 2 \mathrm{Mg}^{2+}+2 \mathrm{OH}^{-}+\mathrm{H}_{2} \\
& 2 \mathrm{H}_{2} \mathrm{O}+2 \mathrm{e}^{-} \rightarrow \mathrm{H}_{2}+2 \mathrm{OH}^{-} \\
& 2 \mathrm{Mg}^{2+}+4 \mathrm{OH}^{-} \rightarrow 2 \mathrm{Mg}(\mathrm{OH})_{2}
\end{aligned}
$$

Anodic and cathodic reactions of the corrosion process were under activation control, and no diffusion control and passivation behaviour were observed in the cathodic and anodic branches of the polarization curves, respectively.

After electroless coating via $\mathrm{Ce}-\mathrm{V}$ conversion coating, a large ennoblement of the corrosion potential, $E_{\text {corr }}$ (more than $1 \mathrm{~V}$ ) and significant decreases of the anodic and cathodic currents were observed with respect to the bare sample. This fact revealed the good corrosion protection performance of the applied coating. More or less same polarization behaviour was observed for the alloy sample after electroless coating through the chromium oxide pretreatment. The corrosion mechanism of the electroless coatings in the corrosive solution can be mainly described by the following equations:

$$
\begin{aligned}
& 2 \mathrm{Ni} \rightarrow 2 \mathrm{Ni}^{2+}+4 \mathrm{e}^{-} \quad E^{\circ}=-0.250 \mathrm{~V} \text { vs. NHE } \\
& \mathrm{O}_{2}+2 \mathrm{H}_{2} \mathrm{O}+4 \mathrm{e}^{-} \rightarrow 4 \mathrm{OH}^{-} \quad E^{\circ}=+0.401 \mathrm{~V} \text { vs. NHE }
\end{aligned}
$$

The cathodic reaction was under activation control but a pseudo-passivation behaviour can be seen for the anodic reaction in the potential range -0.4 to $-0.3 \mathrm{~V}$, and the anodic current did not change significantly when the anodic overpotential was extended. The values of corrosion current densities (table 1) were obtained by Tafel extrapolation of the cathodic branch of the polarization curves. The cathodic Tafel lines were plotted in the liner region of the cathodic branch of the polarization curves at points about $50 \mathrm{mV}$ more negative than the $E_{\text {corr }}$. It can be seen that the electroless coating applied by $\mathrm{Ce}-\mathrm{V}$ conversion coating treatment exhibits the lowest corrosion current density with a value of only $1.49 \mu \mathrm{A} \mathrm{cm}{ }^{-2}$, which is approximately 15 times less than the value obtained for the bare alloy. Also the obtained value was significantly lower than the value obtained for the electroless coating by chromium oxide pretreatment. The corrosion protection performance of a Ni-P electroless coating on the magnesium alloy mainly depends on its morphology and

Table 1. Corrosion current density and corrosion potential of the bare alloy before and after the conversion and electroless coatings alloy after $1 \mathrm{~h}$ immersion in $3.5 \mathrm{wt} \% \mathrm{NaCl}$ solution.

\begin{tabular}{lcc}
\hline Sample & $E_{\text {corr }}(\mathrm{V} v$ s. saturated $\mathrm{Ag}-\mathrm{AgCl})$ & $j_{\text {corr }}\left(\mu \mathrm{A} \mathrm{cm}{ }^{-2}\right)$ \\
\hline Bare alloy & -1.495 & 22.59 \\
Conversion coating & -1.521 & 5.27 \\
Electroless coating $(\mathrm{Cr})$ & -0.455 & 1.85 \\
Electroless coating $(\mathrm{Ce}-\mathrm{V})$ & -0.439 & 1.49 \\
\hline
\end{tabular}



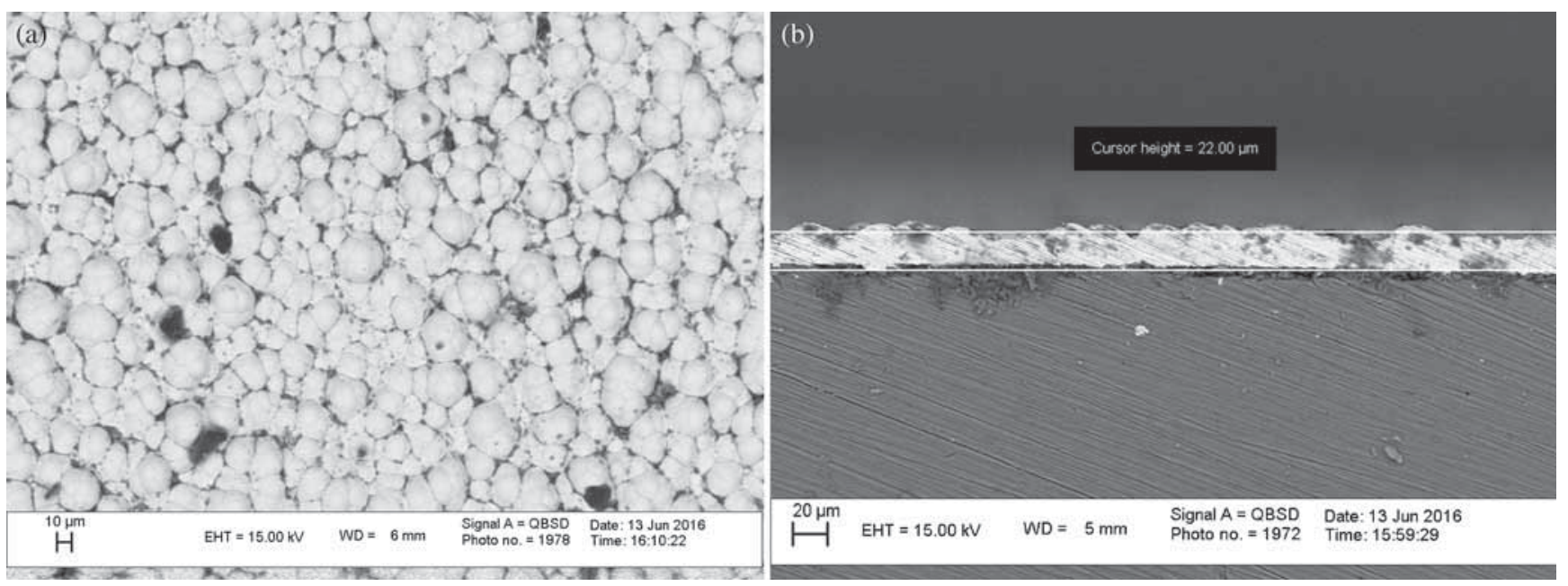

Figure 5. (a) Surface and (b) cross-sectional morphologies of the Ni-P coating on the chromium oxide pretreatment.

thickness. Therefore, the surface and cross-sectional morphologies of the Ni-P coating on chromium oxide pretreatment were also obtained (figure $5 \mathrm{a}$ and $\mathrm{b}$, respectively) and the results were compared with those obtained for the Ni-P on $\mathrm{Ce}-\mathrm{V}$ pretreatment to explain the difference between their anticorrosion performances. As can be seen, the thickness of the Ni-P coating on chromium oxide pretreatment is not significantly different from the thickness of the $\mathrm{Ni}-\mathrm{P}$ coating on $\mathrm{Ce}-\mathrm{V}$ conversion coating, indicating that the pretreatment does not change the plating rate. However, the Ni-P coating on chromium oxide pretreatment shows more nodular and relatively incompact structure, which facilitates the penetration of corrosive electrolyte through the grain boundaries.

\subsection{Micro-hardness}

The average micro-hardness value of the electroless coating applied by $\mathrm{Ce}-\mathrm{V}$ pretreatment was about $458 \mathrm{VHN}$, which is far higher than that of the AM60B alloy substrate (about $83 \mathrm{VHN}$ ). The alloy sample possesses only about $18 \%$ microhardness of the electroless coating, indicating a large difference in micro-hardness. However, the micro-hardness value of the electroless coating obtained by chromium oxide pretreatment was about $608 \mathrm{VHN}$, which is obviously higher than that of the coating obtained by $\mathrm{Ce}-\mathrm{V}$ pretreatment.

\subsection{Porosity test}

As mentioned before, stable and noble corrosion potential around $-0.350 \mathrm{~V}$ was observed for the electroless-plated sample during the first $13 \mathrm{~h}$ of immersion in the corrosive solution, indicating that the coating is completely porefree. Also it is evident from the cross-sectional SEM image (figure 2c) that there are no penetrable pores in the matrix of the coating. However, porosity test was carried out as described in Section 2.6 to support the results of the OCP measurements and morphological studies. Figure $6 a$ and $b$
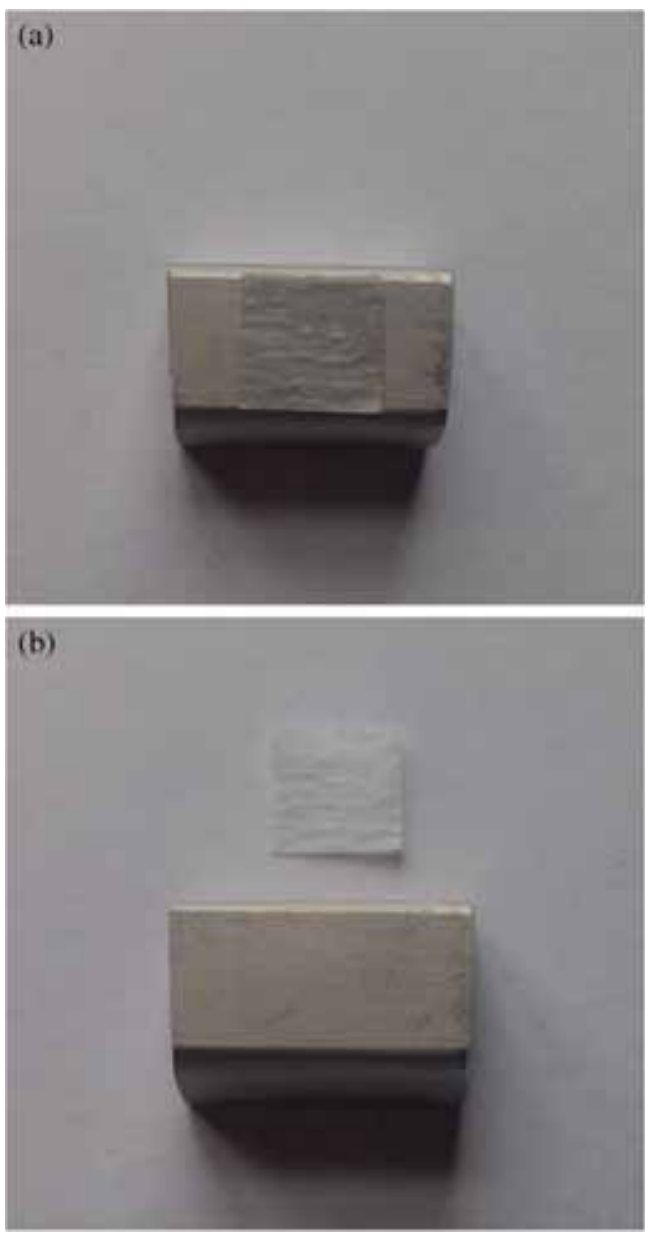

Figure 6. Digital camera images of the Ni-P coating (a) before and (b) after removing the soaked filter paper.

shows digital camera images of the plated sample before and after removing the soaked filter paper, respectively. As is obvious there is no red spot or area on the surface. This is related to the thick, compact and pore-free structure, which impedes the penetration of the corrosive solution at short times. 


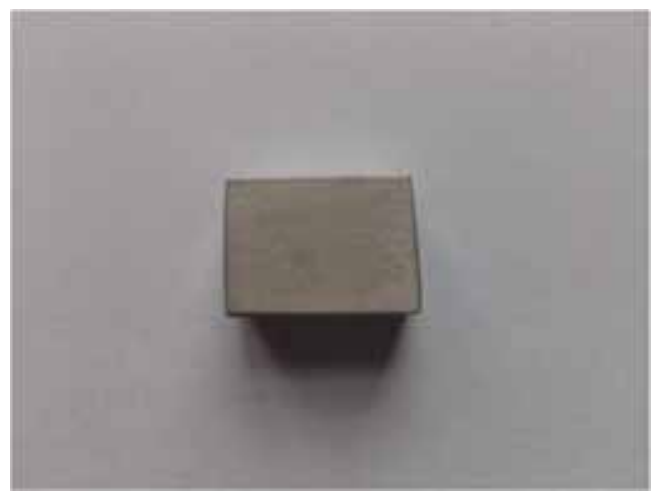

Figure 7. Digital camera image of the Ni-P coating after 30-cycle thermal shock test.

\subsection{Adhesion test}

From the cross-sectional image of the coated sample it appears that the adhesion between the Ni-P coating and the magnesium alloy substrate is strong. However, thermal shock test was carried out to evaluate the adhesion of the electroless coating. Thermal shock test was repeated for 30 cycles as described in Section 2.6. A digital camera image of the coated sample after thermal shock test is shown in figure 7. As is clear, there is no crack, blister or other evidence of poor adheion such as peeling on the surface, indicating suitable adhesion between the electroless coating and magnesium alloy substrate.

\section{Conclusion}

A uniform, dense and pore-free electroless Ni-P coating was successfully applied on AM60B magnesium alloy via environmentally acceptable $\mathrm{Ce}-\mathrm{V}$ pretreatment. The electroless coating showed a spherical nodular morphology with random distribution of the nodule size. Also, the electroless coating showed semi-amorphous microstructure due to moderate concentration of the phosphorus. The corrosion resistance of the bare alloy was significantly increased by application of the electroless coating. Moreover, the coating showed better corrosion protection performance than the coating obtained by chromium oxide pretreatment. Micro-hardness value of the bare alloy was significantly increased after application of the electroless coating. However, the electroless coating showed lower micro-hardness value than the coating obtained by chromium oxide pretreatment. The result of the porosity test revealed that the applied $\mathrm{Ni}-\mathrm{P}$ coating is porefree. Moreover, the results of the thermal shock test showed that the adhesion between the electroless coating and the alloy substrate is suitable.

\section{References}

[1] Zhang W X, Huang N, He J G, Jiang Z H, Jiang Q and Lian J S 2007 Appl. Surf. Sci. 2535116

[2] Zhang W X, Jiang Z H, Li G Y, Jiang Q and Lian J S 2008 Surf. Coat. Technol. 2022570
[3] Mu S, Du J, Jiang H and Li W 2014 Surf. Coat. Technol. 254 364

[4] Gray J E and Luan B 2002 J. Alloys Compd. 33688

[5] Zhang S, Li Q, Yang X, Zhong X, Dai Y and Luo F 2010 Mater. Charact. 61269

[6] Shu X, Wang Y, Peng J, Yan P, Yan B, Fang X and Xu Y 2015 Int. J. Electrochem. Sci. 101261

[7] Lei X, Yu G, Gao X, Ye L, Zhang J and Hu B 2011 Surf. Coat. Technol. 2054058

[8] Shao Z, Cai Z, Hu R and Wei S 2014 Surf. Coat. Technol. 24942

[9] Elsentriecyz H H and Azumi K 2009 J. Electrochem. Soc. 156 D70

[10] Zhang H, Wang S, Yao G and Hua Z 2009 J. Alloys Compd. 474306

[11] Zhang W X, He J G, Jiang Z H, Jiang Q and Lian J S 2007 Surf. Coat. Technol. 2014594

[12] Lian J S, Li G Y, Niu L Y, Gu C D, Jiang Z H and Jiang Q 2006 Surf. Coat. Technol. 2005956

[13] Huo H, Li Y and Wang F 2004 Corros. Sci. 461467

[14] Cuia X, Jin G, Li Q, Yang Y, Li Y and Wang F 2010 Mater. Chem. Phys. 121308

[15] Sudagar J, Jian-she L, Xiao-min C, Peng L and Ya-qin L 2011 Trans. Nonferrous Met. Soc. China 21921

[16] Yu L, Huang W and Zhao X 2011 J. Alloys Compd. 5094154

[17] Yan D, Yu G, Hu B, Zhang J, Song Z and Zhang X 2015 J. Alloys Compd. 653271

[18] Pommiers S, Frayret J, Castetbon A and Potin-Gautier M 2014 Corros. Sci. 84135

[19] Dabala M, Brunelli K, Napolitani E and Magrini M 2003 Surf. Coat. Technol. 172227

[20] Ardelean H, Frateur I and Marcus P 2008 Corros. Sci. 501907

[21] Rudd A L, Breslin C B and Mansfeld F 2000 Corros. Sci. 42275

[22] Tang J L, Han Z Z, Zuo Y and Tang Y M 2011 Appl. Surf. Sci. 2572806

[23] Li L J, Lei J L, Yu S H, Tian Y J, Jiang Q Q and Pan F S 2008 J. Rare Earth 26383

[24] Monternor M F, Simões A M and Carmezim M J 2007 Appl. Surf. Sci. 2536922

[25] Yang K H, Ger M D, Hwu W H, Sung Y and Liu Y C 2007 Mater. Chem. Phys. 101480

[26] Hamdy A S, Doench I and Möhwald H 2012 Surf. Coat. Technol. 2063686

[27] Hamdy A S, Doench I and Möhwald H 2011 Prog. Org. Coat. 72387

[28] Hamdy A S, Doench I and Möhwald H 2011 Electrochim. Acta 562493

[29] Jiang X, Guo R and Jiang S 2015 Appl. Surf. Sci. 341166

[30] Liu J, Wang X, Tian Z, Yuan M and Ma X 2005 Appl. Surf. Sci. 356289

[31] Curioni M 2014 Electrochim. Acta 120284

[32] Song Z, Xie Z, Yu G, Hu B, He X and Zhang X 2015 J. Alloys Compd. 623274

[33] Tarozaite R 2005 Chemija 168

[34] Wang X C, Cai W B, Wang W J, Liu H T and Yu Z Z 2003 Surf. Coat. Technol. 168300

[35] Cao F H, Len V H, Zhang Z and Zhang J Q 2007 Russ. J. Electrochem. 43837

[36] Song G, Atrens A, Stjohn D, Nairn J and Li Y 1997 Corros. Sci. 39855 